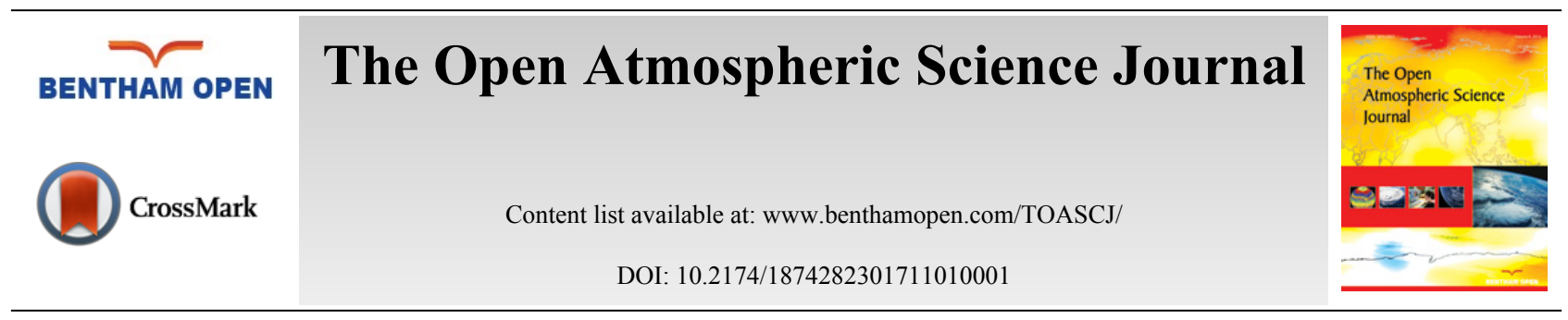

RESEARCH ARTICLE

\title{
Evaluation of Wet Mapping Functions Used in Modeling Tropospheric Propagation Delay Effect on GPS Measurements
}

\author{
Sobhy Abdel-Monam Younes* \\ Associate professor of surveying and geodesy, Dept. of Public Works Engineering, Faculty of Engineering, Tanta \\ University, Tanta City, Egypt
}

Received: January 03, 2017

Revised: March 10, 2017

Accepted: March 13, 2017

\begin{abstract}
:
Background:

The author compares several methods to map the a priori wet tropospheric delay of GNSS signals in Egypt from the zenith direction to lower elevations.
\end{abstract}

\section{Methods and Materials:}

The author compared the following mapping techniques against ray-traced delays computed for radiosonde profiles under the assumption of spherical symmetry: Saastamoinen, Hopfield, Black, Chao, Ifadis, Herring, Niell, Moffett, Black and Eisner and UNBabc mapping functions. Radiosonde data were computed from radiosonde stations at the Egyptian stations; in the south of Egypt, near the Mediterranean Sea, and near the Red Sea over a period of 5 years (2000-2005), most of the stations launched radiosonde twice daily, every day of the year. Moreover, data is received from the Egyptian Meteorology Authority.

\section{Results and Conclusion:}

The results indicate that currently, the saastamoinen mapping function should be used for all geodetic applications in Egypt, and if necessary, the Chao and Moffett mapping functions can serve as an acceptable replacement without introducing a significant bias into the station position.

Keywords: Ionospheric and Tropospheric Delay, Wet Mapping Function, Saastamoinen Model, Egyptian Meteorological Authority (EMA).

\section{INTRODUCTION}

The tropospheric refraction, among other error sources like the ionospheric refraction, multipath and signal obstructions, is one of the main factors limiting accuracy of the Global Navigation Satellite Systems (GNSS) measurements. Nowadays, one can observe the increasing demand of reliable, accurate and fast results from precise GNSS positioning. GNSS technique is commonly used in geodesy, land surveying, civil engineering, deformation monitoring and structural monitoring where precise, centimeter-level accuracy height of sites is often compulsory. Unfortunately, the tropospheric refraction is strongly correlated with the vertical coordinate component of a site and affects this component rather than the horizontal ones [1].

Satellite signals from GNSS satellites suffer from the influence of the Earth's atmosphere, which deteriorates the accuracy of the obtained positions. The major part of this phenomenon is caused by the ionized part of the upper atmosphere and is termed the ionospheric refraction. Fortunately, an application of dual (or multi) frequency signals allows GNSS users to mitigate this impact [2]. Additionally, electromagnetic waves are refracted in the neutral, lower

\footnotetext{
* Address correspondence to this author at the Dept. of Public Works Engineering, Faculty of Engineering, Tanta University, Tanta City, Egypt; Tel: 040 3315860; Fax: (+20) 0403315860; E-mail: Sobhi100@yahoo.com
} 
part of the Earth's atmosphere. Influence of the neutral atmosphere is commonly referred to as the tropospheric refraction [3]. In detail, the GNSS signal slows down and its path is getting curved. By contrast to the ionospheric delay, this influence cannot be eliminated using the dual frequency relationship. It is because of non-dispersive nature of the neutral atmosphere for microwave frequencies. Changes in speed and path cause delay in travel of signal in comparison to travel in vacuum. The delay due to the tropospheric refraction may be expressed as [4]:

$$
D_{\text {trop }}=\int n(s) d s-\int d s
$$

where, $D_{\text {trop }}$ is the tropospheric delay and $n(s)$ is the refractive index as a function of path length. It is common to divide the troposphere into hydrostatic and wet part due to the water vapor content. The tropospheric zenith total delay may be expressed as a sum of hydrostatic and wet zenith delays:

$$
Z T D=Z H D+Z W D
$$

where, $Z T D$ is the zenith total delay, $Z H D$ the zenith hydrostatic delay, and $Z W D$ the zenith wet delay.

Significant errors may be introduced when ZTDs are mapped into slant tropospheric delays with mapping functions. Converting (mapping) zenith delays into slant delays with the use of proper and accurate mapping function is of crucial interest because for low elevation angles ( $<15$ degrees) the slant delay is ten times larger than for zenith direction [5].

The slant total delays toward the satellite are computed using the following formula [4]:

$$
S T D(e)=Z H D \times m d(e)+Z W D \times m w(e),
$$

where, $e$ is the elevation angle towards the satellite, $\operatorname{STD}(e)$ the slant total delay, ZHD the zenith hydrostatic delay, $m d(e)$ the mapping function for the hydrostatic delay, $Z W D$ the zenith wet delay, and $m w(e)$ is the mapping function for the non-hydrostatic delay.

The hydrostatic delay is caused by atmospheric gases that are in hydrostatic equilibrium. This is usually the case for dry gases and part of the water vapor. This part of the delay can very well be modeled based on the surface air pressure. The wet delay, caused by water vapor that is not in hydrostatic equilibrium, is the source of our problems. We can derive models for this delay based on the partial pressure of water vapor or relative humidity at the surface, but these models have low accuracy and need empirical constants that may vary widely with location and time of year.

Most works concerning the assessment and development of tropospheric delay models and mapping functions has been reported by Forgues [6], Mendes [7], Langely and Guo [8] and others scientists. Forgues [6] simulated the impact of 15 mapping functions on GPS positioning as a function of a large number of factors such as the elevation angle, the site location, the duration of the observation session, and the estimation of tropospheric parameters. Using the Mapping Temperature Test (Herring [9],) function as reference, she concluded that the functions by Davis et al [10], Lanyi [11], Ifadis [12], and Niell [13] performed the best for short and long baselines. Mendes [7] presents comprehensive assessment of the most significant models and mapping functions developed in the last three decades against ray tracing data from 50 stations. He optimized the performance of mapping function based on some developed models. He recommended the Saastamoinen model to be used in predicting the zenith dry and wet delay. If meteorological measurements aren't available, He recommended Niell mapping function [13] to be used in modeling the elevation dependence of the zenith delay. If that information is available, and for elevation angle above $6^{\circ}$, Ifadis [12], Lanyi [11], and Herring [9] mapping functions will likely lead to identical results. For elevation angles below $6^{\circ}$ the Lanyi mapping function [11] is no longer recommended.

Langely and Guo [8] reported on an investigation to determine the error of several mapping functions at elevation angles as low as $2^{\circ}$ and presented a new model, UNBabc, which has better low-elevation angles performance and requires only slightly more computation time. They concluded that UNBabc is the best candidate for a Global Navigation Satellite Systems (GNSS) receiver built-in mapping function as it takes much less time to compute than Niell mapping function [13] does and has much better accuracy than Black and Eisner (B\&E) [14] mapping function.

But most standard tropospheric models and mapping functions were experimentally derived using available radiosonde data, which were mostly observed on the European and North American continents. There is therefore a strong motivation to evaluate the accuracy of the current strategies proposed for wet tropospheric delay modeling especially for atmospheric conditions of Egypt. 
The main research contribution from this work is the identification, classification, and comparison of alternative wet mapping function for the ray-path and the atmospheric structure employed in ray-tracing. It is a two-part contribution, parts that we now discuss. Firstly, a numerical integration based model is devoted to determine wet tropospheric delay at different zenith angles, which represent the benchmark values for the assessment of wet tropospheric delay models and mapping functions used for tropospheric modeling in GPS data in Egypt. Secondly, an assessment of ten wet mapping functions and functional formulations for describing both the elevation angle and azimuth-dependence of the wet tropospheric delay is performed. These mapping functions are Saastamoinen, Hopfield, Black, Chao, Ifadis, Herring, Niell, Moffett, Black and Eisner and UNBabc mapping functions. The basic motivation for this assessment of ten mapping functions through comparison with ray tracing through radiosonde data is determining the better wet mapping functions in the analysis of space geodetic data.

\section{MAPPING FUNCTIONS}

The mapping function, $\mathrm{m}(\varepsilon)$, is defined as the ratio of the electrical path length through the atmosphere at geometric elevation $\varepsilon$, to the electrical path length in the zenith direction. A mapping function is used to map the zenith delay to estimate the slant tropospheric delay. Several mapping functions have been developed in the past 20 years. The simplest mapping function is given by $1 / \sin (\varepsilon)$ [15], the cosecant of the elevation angle. In this derivation, it is assumed that spherical constant height surfaces could be approximated as planar surfaces. This is an accurate approximation only for high elevation angles and with a small degree of bending. More complex mapping functions have been developed, and different mapping functions may be used for the hydrostatic versus wet delays. Brief descriptions of the main features of various wet mapping functions are given in the following sub-sections.

\subsection{Saastamoinen Model}

Saastamoinen developed a total delay model for the troposphere from which a "neutral" mapping function can be derived. It is given here because it can be applied for the wet delay as well as for the dry delay and has been popular among broad parts of the GPS user community in the past. Several stages of refinement exist for Saastamoinen's approach [16].

$$
D_{w e t}^{\text {trop }}(\varepsilon)=\frac{0.002277}{\cos (z)}\left[\frac{1255}{T_{0}}+0.05\right] e_{0} \text {, }
$$

where,

$z$ : apparent (“actual") zenith angle at the surface (antenna),

$\varepsilon:$ elevation angle (degree),

$T_{0}$ : surface temperature in $\left(\mathrm{K}^{\circ}\right)$,

$e_{0}$ : partial water vapor pressure in $(\mathrm{mb})$.

\subsection{Hopfield Model}

Hopfield used real data covering the whole Earth. He has empirically found a representation of the wet refractivity as a function of the height $\boldsymbol{h}$ above the surface by,

$$
N_{w}^{\text {trop }}(h)=N_{w 0}^{t r o p}\left[\frac{h_{w}-h}{h_{w}}\right]^{4}
$$

where, the mean value $\boldsymbol{h}_{w}=\mathbf{1 1 0 0 0} \mathrm{m}$ is used.

The result equations for wet components in $(\mathrm{m})$ are [3];

$$
D_{w}^{t r o p}(\varepsilon)=\frac{10^{-6}}{5} \frac{-12.96 T+3.718 * 10^{5}}{\sin \sqrt{\varepsilon^{2}+2.25}} \frac{e_{0}}{{T_{0}}^{2}} 1000
$$

where, $\boldsymbol{T}_{\boldsymbol{0}}$ and $\boldsymbol{e}_{\boldsymbol{0}}$ are measuring at the observation location and $\boldsymbol{\varepsilon}$ is the elevation angle. 


\subsection{Black Model}

The wet mapping functions derived by Black are based on the quartic profiles developed by Hopfield and use the equivalent heights proposed by Hopfield [3]. This mapping function was recommended for elevation angles above $5^{\circ}$ and the slant wet delay is [17]:

$$
D_{\text {wet }}^{\text {trop }}(\varepsilon)=\frac{0.07465 \cdot \frac{e_{0}}{T_{0}^{2}} \cdot H_{w}}{\sqrt{1-\left\{\frac{\cos \varepsilon}{1+L_{c} \cdot \frac{H_{w}}{r}}\right\}^{2}}}-\frac{1.92}{\varepsilon^{2}+0.6^{\circ}},
$$

where:

$e_{0}$ : partial water vapor pressure at site in $[\mathrm{mb}]$,

$T_{0}$ : temperature at site in $\left[\mathrm{K}^{\circ}\right]$,

$H_{\mathrm{w}}$ : upper boundary height for the wet delay/height of the tropopause,

$r$ : radial distance from earth center to site,

$\varepsilon$ : elevation angle in [degrees],

The $H_{\mathrm{w}}$ in eq. (7) can be approximated with help of surface temperature $t$ as:

$$
H_{w}=7.508+2.421 \cdot \exp \left(\frac{t_{0}}{22.90}\right)
$$

and the scale factor $\mathrm{L}_{\mathrm{c}}$ in eq, (7) is:

$$
L_{c}=0.167-\left(0.076+0.00015 t_{0}\right) \cdot \exp (-0.3 e) .
$$

\subsection{Chao Wet Mapping Function}

Marini gave the elevation angle dependence of the atmospheric delay in the form a continued fraction, in terms of the sine of elevation angle $\varepsilon[18]$ :

$$
m(\varepsilon)=\frac{1}{\sin \varepsilon+\frac{a}{\sin \varepsilon+\frac{b}{\sin \varepsilon+\frac{c}{\sin \varepsilon+\cdots}}}}
$$

where, the coefficients $a, b, c \ldots$ are constants or linear functions which depend on surface pressure, temperature, lapse rates, and height.

In the Chao mapping functions, the continued fraction in eq. (10) is truncated to second order terms and the second order $\sin \varepsilon$ is replaced by $\tan \varepsilon$, and the coefficients a and b are determined from empirical data. The wet mapping functions are expressed as follows [19]:

$$
m(\varepsilon)_{w e t}=\frac{1}{\sin \varepsilon+\frac{0.00035}{\tan \varepsilon+0.017}},
$$

\subsection{Ifadis Wet Mapping Function}

The global wet mapping function of Ifadis adopts the mapping function type [12]:

$$
m(\varepsilon)_{w e t}=\frac{1+\frac{a}{1+\frac{b}{1+c}}}{\sin \varepsilon+\frac{a}{\sin \varepsilon+\frac{b}{\sin \varepsilon+c}}},
$$


The wet mapping function coefficients are

$$
\begin{aligned}
& a=0.0005236+0.2471 .10^{-6}\left(P_{0}-1000\right)-0.1724 .10^{-6}\left(t_{0}-15\right)+0.1328 .10^{-4} \cdot \sqrt{e_{0}}, \\
& b=0.001705+0.7384 .10^{-6}\left(P_{0}-1000\right)-0.3767 .10^{-6}\left(t_{0}-15\right)+0.2147 .10^{-4} \cdot \sqrt{e_{0}}, \\
& c=0.05917, \\
& \text { since, } \\
& P_{0}: \text { pressure at site in }[\mathrm{mb}] \\
& e_{0}: \text { partial water vapor pressure at site in }[\mathrm{mb}] \\
& t_{0}: \text { temperature at site in }\left[{ }^{\circ} \mathrm{C}\right]
\end{aligned}
$$

\subsection{Herring Wet Mapping Function}

Herring has developed both hydrostatic and wet mapping functions by fitting to radiosonde data from several North American stations ranging in geographic latitude from $27^{\circ} \mathrm{N}$ to $65^{\circ} \mathrm{N}$ for elevation angles down to $3^{\circ}$. The mapping function's coefficients depend linearly on surface temperature, the cosine of the station latitude, and the height of the station above the geoid. The expression for the mapping function is given below [9]:

$$
m(\varepsilon)_{w e t}=\frac{1+\frac{a}{1+\frac{b}{1+c}}}{\sin \varepsilon+\frac{a}{\sin \varepsilon+\frac{b}{\sin \varepsilon+c}}},
$$

where, $\mathrm{a}, \mathrm{b}$, and c are constants or linear functions, and can be determined by:

$$
\begin{aligned}
a & =\left[0.583-0.011 \cos \varnothing-0.000052 H_{0}+0.0014\left(t_{0}-10\right)\right] .10^{-3} \\
b & =\left[1.402-0.102 \cos \varnothing-0.000101 H_{0}+0.0020\left(t_{0}-10\right)\right] .10^{-3} \\
c & =\left[45.85-1.91 \cos \varnothing-0.00129 H_{0}+0.015\left(t_{0}-10\right)\right] .10^{-3}
\end{aligned}
$$

where:

$t_{0}$ : temperature at site in $\left[{ }^{\circ} \mathrm{C}\right]$

$\varphi$ : latitude of site

$H_{0}$ : height of site above sea level in $[\mathrm{km}]$

\subsection{Niell Wet Mapping Function}

The Neill mapping functions have no parameterization in terms of meteorological conditions, and they provide a better fit and give better accuracy for elevation angles down to $3^{\circ}$. The form adopted for the mapping functions is the continued fraction with three coefficients $(a, b, c)$. The wet mapping function depends only on the site latitude [13]. The expressions for the wet mapping functions are given below:

$$
m(\varepsilon)_{w e t}=\frac{\frac{1}{1+\frac{a_{w e t}}{1+\frac{b_{w e t}}{1+c_{W e t}}}}}{\sin \varepsilon+\frac{a_{w e t}}{\sin \varepsilon+\frac{b_{w e t}}{\sin \varepsilon+c_{w e t}}}},
$$

where: $\varepsilon$ is the elevation angle, and for the wet mapping function, only an interpolation in latitude for each parameter is needed. The average values of $a_{\text {wet }}, b_{\text {wet }}$ and $c_{\text {wet }}$ and their amplitudes are given in (Table 1). 
Table 1. Coefficients of the Niell wet mapping function.

\begin{tabular}{|c|c|c|c|c|c|}
\hline Coefficients & $\boldsymbol{\phi}=\mathbf{1 5}^{\circ}$ & $\boldsymbol{\phi}=\mathbf{3 0}^{\circ}$ & $\boldsymbol{\phi}=\mathbf{4 5}^{\circ}$ & $\boldsymbol{\phi}^{\circ} \mathbf{6 0}^{\circ}$ & $\boldsymbol{\phi}^{\circ} \mathbf{7 5}^{\circ}$ \\
\hline $\mathrm{a}$ & $5.8021897 \mathrm{e}^{-4}$ & $5.6794847 \mathrm{e}^{-4}$ & $5.8118019 \mathrm{e}^{-4}$ & $5.9727542 \mathrm{e}^{-4}$ & $6.1641693 \mathrm{e}^{-4}$ \\
\hline $\mathrm{b}$ & $1.4275268 \mathrm{e}^{-3}$ & $1.5138625 \mathrm{e}^{-3}$ & $1.4572752 \mathrm{e}^{-3}$ & $1.5007428 \mathrm{e}^{-3}$ & $1.7599082 \mathrm{e}^{-3}$ \\
\hline $\mathrm{c}$ & $4.3472961 \mathrm{e}^{-2}$ & $4.6729510 \mathrm{e}^{-2}$ & $4.3908931 \mathrm{e}^{-2}$ & $4.4626982 \mathrm{e}^{-2}$ & $5.4736038 \mathrm{e}^{-2}$ \\
\hline
\end{tabular}

\subsection{Moffett Wet Mapping Function}

Simplified approximations of the Hopfield mapping functions are presented in [20]. These simplified mapping functions have been used extensively, as they depend on the elevation angle only as in eq. (15):

$$
m(\varepsilon)_{w e t}=\frac{1}{\sin \left(\sqrt{\varepsilon^{2}+2.25^{\circ}}\right)}
$$

\subsection{Black and Eisner MF}

The Black and Eisner mapping function for the total delay is a further modification of Black's, and is expressed as a simple geometrical model (16), which depends on the elevation angle only, with one fitted parameter [14]:

$$
m(\varepsilon)_{w e t}=\frac{1}{\sqrt{1-\left\langle\frac{\cos \epsilon}{1+0.001}\right\rangle^{2}}}
$$

This mapping function is claimed to be valid for elevation angles greater than $7^{\circ}$.

\subsection{UNBabc MF}

Jiming Gue and Richard B. Langley were produced a mapping Function called (UNBabc) had a 3-term continued fraction form as in eq. (10) [8]. From a series of analyses, they concluded that parameter (a) is sensitive to the orthometric height $(H)$ and latitude $(\varphi)$ of the station where as parameters $\mathrm{b}$ and could be represented by constants. The least-squares estimated parameters for the wet mapping function:

$$
\begin{aligned}
& a_{\mathrm{w}}=0.61120-0.035348 H-0.01526 \cos \varphi / 1000 \\
& \mathrm{~b}_{\mathrm{w}}=0.0018576 \\
& \mathrm{c}_{\mathrm{w}}=0.062741
\end{aligned}
$$

The mapping functions assessed in this study and the corresponding codes and references used in the tables of results are listed in (Table 2 ).

Table 2. Summary table of the main features of wet mapping functions.

\begin{tabular}{|c|c|c|c|}
\hline Code & Reference & Impute parameters & $\boldsymbol{\varepsilon}_{\boldsymbol{m i n}}{ }^{\circ}$ \\
\hline$S A$ & Saastamoinen (1987) & $\boldsymbol{z}, \boldsymbol{T}, \boldsymbol{e}_{\boldsymbol{o}}$ & $\mathbf{1 0}^{\circ}$ \\
\hline$H O$ & Hopfield (1971) & $\boldsymbol{\varepsilon}, \boldsymbol{T}, \boldsymbol{e}_{\boldsymbol{o}}$ & $* *$ \\
\hline$B L$ & Black (1978) & $\boldsymbol{\varepsilon}, \boldsymbol{T}, \boldsymbol{e}_{\boldsymbol{o}}, \boldsymbol{r}$ & $\mathbf{5}^{\circ}$ \\
\hline$C H$ & Chao (1972) & $\boldsymbol{\varepsilon}$ & $\mathbf{1 0}^{\circ}$ \\
\hline$I F$ & Ifadis (1986) & $\boldsymbol{\varepsilon}, \boldsymbol{t}, \boldsymbol{\boldsymbol { e } _ { \boldsymbol { o } } , \boldsymbol { P }}$ & $\mathbf{2}^{\circ}$ \\
\hline$H E$ & Herring (1992) & $\boldsymbol{\varepsilon} \boldsymbol{t}, \boldsymbol{\varphi}, \boldsymbol{H}_{\boldsymbol{o}}$ & $\mathbf{3}^{\circ}$ \\
\hline$N I$ & Niell (1993) & $\boldsymbol{\varepsilon}, \boldsymbol{\varphi}$ & $\mathbf{3}^{\circ}$ \\
\hline$M O$ & Moffett (1973) & $\boldsymbol{\varepsilon}$ & $\mathbf{2}^{\circ}$ \\
\hline$B \& E$ & Black and Eisner (1984) & $\boldsymbol{\varepsilon}$ & $7^{\circ}$ \\
\hline$U N B a b c$ & Gue J. and Langley R. (2003), & $\boldsymbol{\varepsilon}, \boldsymbol{\varphi}, \boldsymbol{H}$ & $2^{\circ}$ \\
\hline
\end{tabular}

where: $\varphi$ is the station latitude, $H$ is the station height, $r$ is the effective radius of the station, $T$ is the temperature at site in $\mathrm{K}^{\circ}, t$ is the temperature at site in ${ }^{\circ} \mathrm{C}, e$ is the partial water vapor pressure in $(\mathrm{mb}), \mathrm{z}$ is the zenith angle and $\varepsilon$ is the elevation angle. ** Means that: not specified or valid for any elevation angle.

Saastamoinen model, Hopfield model and black model give the wet slant tropospheric delay directly but in other mapping functions used for the wet zenith tropospheric delay, the Saastamoinen model eq. (4) [21]. 


\section{EXPERIMENTAL PROCEDURES}

\subsection{Research Methodology}

Fig. (1) represents the flow chart followed in this Research. It contains several stages as follows:

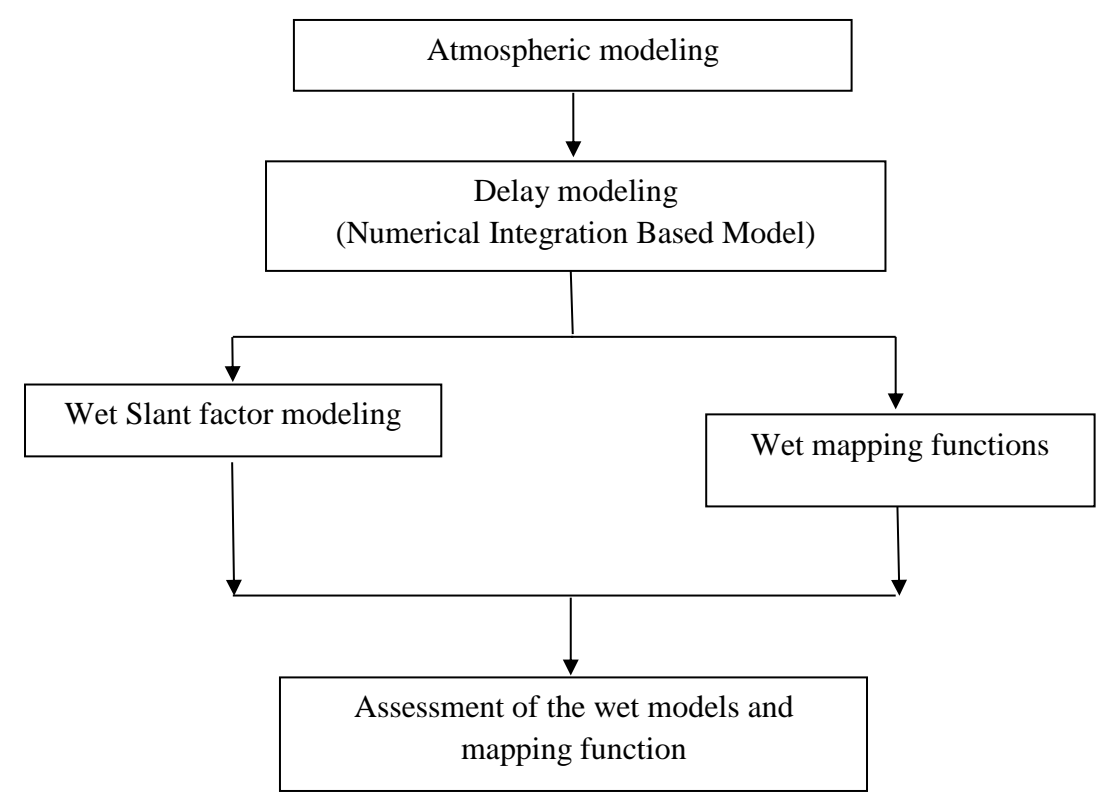

Fig. (1). Diagram of research methodology.

1. Atmospheric modeling, it presents height profiles for pressure, temperature, and humidity.

2. Delay modeling, it aims to determine wet tropospheric delay at different zenith angles for three stations Aswan, Helwan, and Mersa-Matrouh in different times of year in Egypt (Numerical Integration Model).

3. Assessment of prediction models or mapping functions, this stage aims to determine best models and mapping functions which present high accuracy in wet tropospheric delay prediction for Egypt.

\subsection{Ray Trace Model}

In order to evaluate mapping functions, we ray-traced the refractivity profiles computed from the pressure, temperature and relative humidity profiles from balloon flights launched from 5 radiosonde stations at the Egyptian stations in the south of Egypt, near the Mediterranean Sea, and near the Red Sea over a period of 5 years (2000-2005). Most of the stations launched radiosonde twice daily, every day of the year.

When ray-trace methods are used to calculate range and elevation-angle errors, integrals for the bending, electromagnetic ray path, and the straight line path or geometric path (or the sums to which these integrals are reduced by layering) must be calculated for each of the many data points of a satellite pass. The integrals, moreover, must be calculated with great precision since the range error is calculated by taking the difference between the electromagnetic path and the geometric path, two nearly equal numbers.

In the method given by Thayer [22], the number of calculations required over a satellite pass is considerably reduced since the coefficients used to evaluate the integrals are independent of the elevation angle of the ray. The elevation angle at each layer must be calculated for each new ray by using Snell's law, however, and the need for great precision remains.

There are total of 1092 radiosonde profiles for the selected data set. For each profile, the ray tracing was done at elevation angles of $5^{\circ}, 6^{\circ}, 7^{\circ}, 8^{\circ}, 9^{\circ}, 10^{\circ}, 11^{\circ}, 13^{\circ}, 15^{\circ}, 17^{\circ}, 20^{\circ}, 25^{\circ}, 30^{\circ}, 35^{\circ}, 40^{\circ}, 45^{\circ}, 50^{\circ}, 55^{\circ}, 60^{\circ}, 65^{\circ}, 70^{\circ}, 75^{\circ}, 80^{\circ}$, $85^{\circ}$ and $90^{\circ}$ to generate wet slant delays. The geographical distribution of the 5 stations is shown in [21]. The orthometric heights of the stations range from $32 \mathrm{~m}$ to $192 \mathrm{~m}$ slant wet tropospheric propagation delay are showed in (Figs. 2-4). 


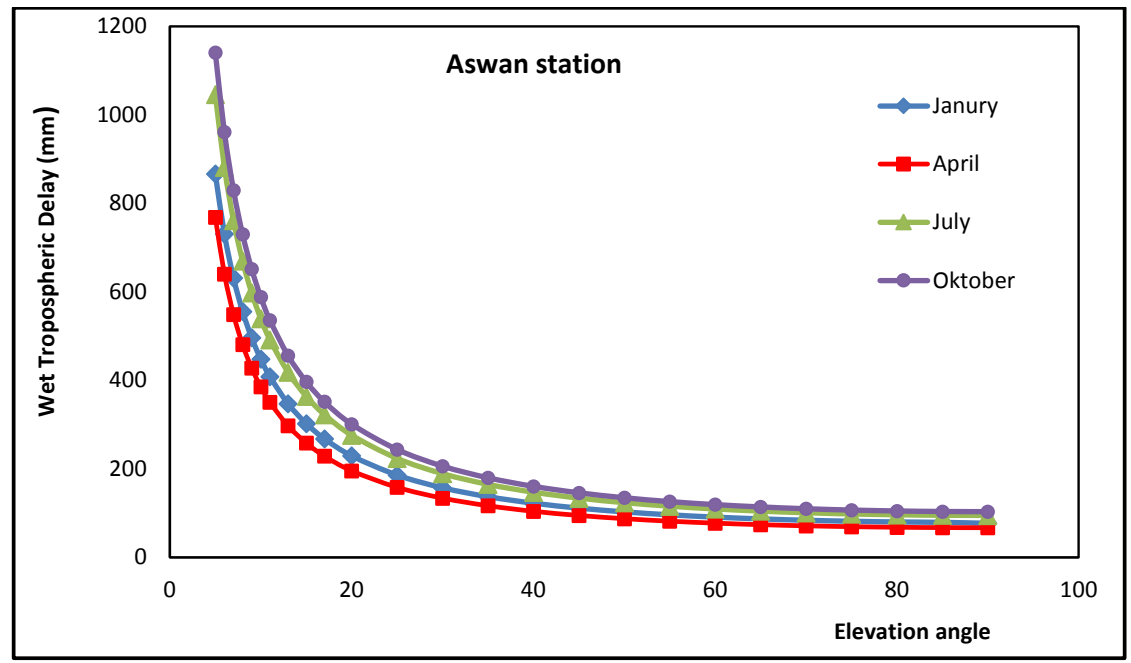

Fig. (2). Wet tropospheric propagation delay errors versus elevation angles at Aswan station (south of Egypt).

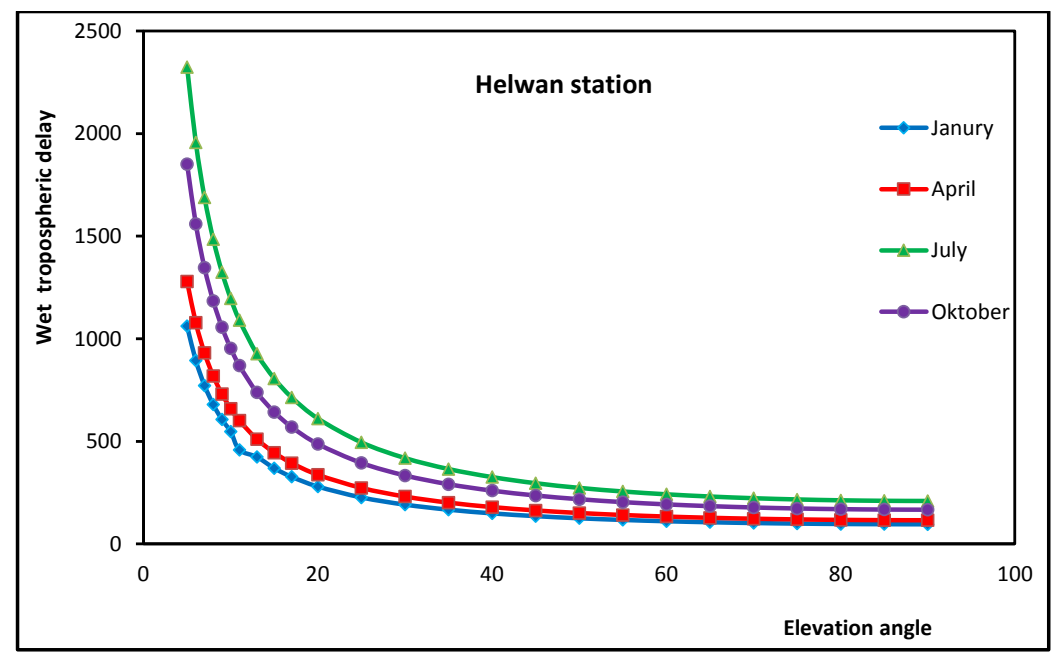

Fig. (3). Wet tropospheric propagation delay errors versus elevation angles at Helwan station (mid of Egypt).

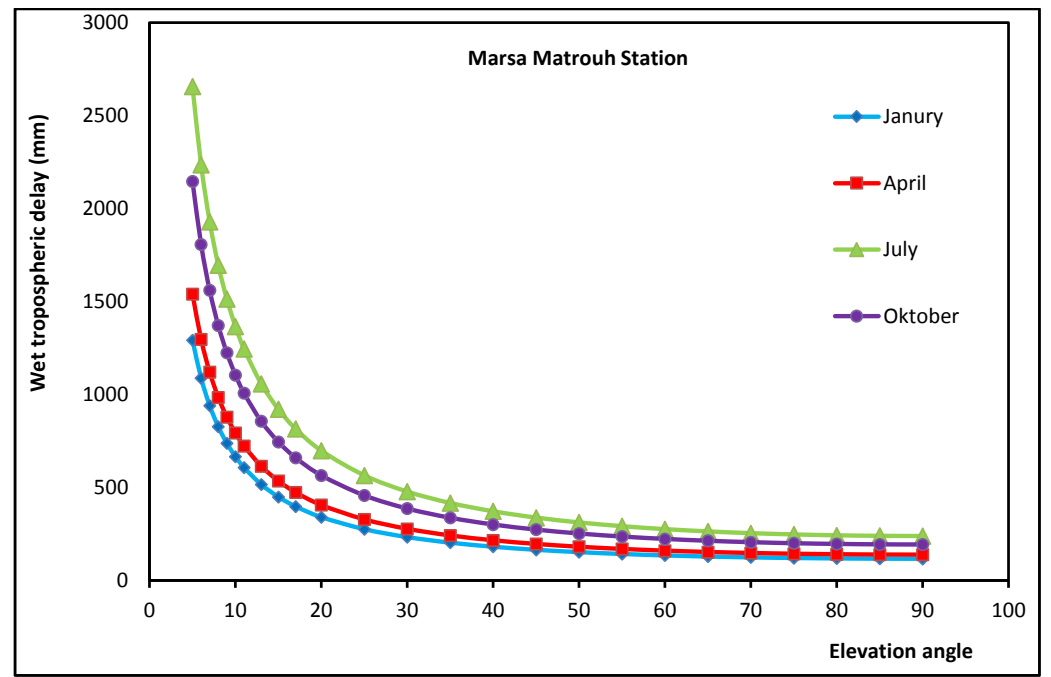

Fig. (4). Wet tropospheric propagation delay errors versus elevation angles at Marsa Matrouh station (north of Egypt). 
Analysis data received from ray-traced model showed that, wet tropospheric delay in Egypt varies from $66.84 \mathrm{~mm}$ to $223.34 \mathrm{~mm}$ at zenith and slant wet delay increase slowly with high elevation angles from $30^{\circ}-90^{\circ}$. At elevation angle $60^{\circ}$, wet delay error varies from min value $77.18 \mathrm{~mm}$ at Aswan station in April to max value $276.34 \mathrm{~mm}$ at Marsa Matrouh station in July month. For elevation angle $30^{\circ}$, it changes from min value 133.69 at Aswan station in April to max value $478.29 \mathrm{~mm}$ at Marsa Matrouh station in July.

For the elevation angles lower than $30^{\circ}$ the slant wet delay errors are increased suddenly. For elevation angles 15 , wet delay error is $258.31 \mathrm{~mm}$ at Aswan station in April (min value) and $921.26 \mathrm{~mm}$ in July at Helwan station (max value). Wet delay errors at elevation angle 10 change from $385.09 \mathrm{~mm}$ to $1366.49 \mathrm{~mm}$. for elevation angle 7; it arrives $1688.86 \mathrm{~mm}$ as min value but arrives $2323.43 \mathrm{~mm}$ as max value at elevation angle 5. Analysis of data in Figs. (2-4) resulted that wet tropospheric delay in Egypt increases from south of Egypt to Cairo region and increases near the Mediterranean Sea. Wet delay in Egypt in summer months is more than other seasons in middle and north of Egypt but in Upper Egypt max wet delay values are measured in autumn months.

\subsection{Wet Delay MF}

Slant delays are computed using the ray-traced vertical delays together with the ten mapping functions and compared to the ray-traced slant delays for elevation angles $5^{\circ}, 6^{\circ}, 7^{\circ}, 8^{\circ}, 9^{\circ}, 10^{\circ}, 11^{\circ}, 13^{\circ}, 15^{\circ}, 17^{\circ}, 20^{\circ}, 25^{\circ}, 30^{\circ}, 35^{\circ}$, $40^{\circ}, 45^{\circ}, 50^{\circ}, 55^{\circ}, 60^{\circ}, 65^{\circ}, 70^{\circ}, 75^{\circ}, 80^{\circ}, 85^{\circ}, 90^{\circ}$ at Aswan station, Helwan station and Marsa Matrouh station in January, April, July, October months and average data over the year.

\section{RESULTS AND DISCUSSION}

The results of the assessment are summarized in Tables (3-7) and the mean biases and rms errors of these mapping functions are showed in (Figs. 5-9).

Table 3. Mean and rms of the wet tropospheric delay errors of the differences between the delays computed using the mapping functions and the ray trace results at $75^{\circ}$ and $85^{\circ}$ elevation angles.

\begin{tabular}{|c|c|c|c|c|c|c|c|c|}
\hline \multirow{2}{*}{ MF } & \multicolumn{9}{|c|}{ Elevation angle 85 } & \multicolumn{4}{c|}{ Elevation angle $\mathbf{7 5}^{\circ}$} \\
\cline { 2 - 9 } & min & max & mean & rms & min & max & mean & rms \\
\hline SA & 4.83 & 16.70 & 11.26 & 3.20 & 4.98 & 17.25 & 11.60 & 3.89 \\
\hline HO & 9.04 & 30.19 & 18.02 & 5.24 & 9.33 & 31.15 & 18.59 & 5.40 \\
\hline BL & 1.18 & -60.95 & -19.18 & 7.15 & 1.22 & -62.85 & -19.78 & 7.38 \\
\hline CH & 4.86 & 16.72 & 11.25 & 3.29 & 5.02 & 17.25 & 4.60 & 3.39 \\
\hline IF & 4.86 & 16.71 & 11.25 & 3.28 & 5.02 & 17.24 & 11.60 & 3.39 \\
\hline HE & 4.86 & 16.72 & 11.25 & 3.28 & 5.02 & 17.24 & 11.60 & 3.39 \\
\hline NI & 4.94 & 16.91 & 11.44 & 3.34 & 5.08 & 17.45 & 11.80 & 3.45 \\
\hline M0 & 4.86 & 16.72 & 11.25 & 3.28 & 5.02 & 17.75 & 11.63 & 3.38 \\
\hline B\&E & 4.86 & 16.72 & 11.28 & 3.29 & 5.02 & 17.24 & 11.60 & 3.38 \\
\hline UNBabc & 4.86 & 16.71 & 11.25 & 3.28 & 5.02 & 17.24 & 11.60 & 3.39 \\
\hline
\end{tabular}

Table 4. Mean and rms of the wet tropospheric delay errors of the differences between the delays computed using the mapping functions and the ray trace results at $45^{\circ}$ and $60^{\circ}$ elevation angles.

\begin{tabular}{|c|c|c|c|c|c|c|c|c|}
\hline \multirow{2}{*}{ MF } & \multicolumn{4}{|c|}{ Elevation angle $60^{\circ}$} & \multicolumn{4}{|c|}{ Elevation angle $45^{\circ}$} \\
\hline & $\min$ & $\max$ & mean & rms & $\min$ & $\max$ & mean & rms \\
\hline SA & 5.55 & 19.23 & 12.93 & 3.78 & 6.80 & 23.49 & 15.78 & 4.61 \\
\hline $\mathrm{HO}$ & 10.41 & 34.74 & 20.73 & 6.03 & 12.77 & 42.28 & 25.38 & 7.38 \\
\hline $\mathrm{BL}$ & 1.35 & -70.10 & -22.07 & 8.23 & 1.60 & -86.08 & -27.03 & 10.08 \\
\hline $\mathrm{CH}$ & 5.60 & 19.26 & 12.95 & 3.78 & 6.89 & 23.59 & 15.85 & 4.63 \\
\hline IF & 5.60 & 19.25 & 12.95 & 3.78 & 6.90 & 23.61 & 15.87 & 4.63 \\
\hline $\mathrm{HE}$ & 5.60 & 19.25 & 12.95 & 3.78 & 6.90 & 23.62 & 15.87 & 4.63 \\
\hline $\mathrm{NI}$ & 5.68 & 19.48 & 13.17 & 3.85 & 7.00 & 23.89 & 16.14 & 4.72 \\
\hline M0 & 5.60 & 19.25 & 12.95 & 3.78 & 6.89 & 23.58 & 15.85 & 4.63 \\
\hline$B \& E$ & 5.60 & 19.27 & 12.96 & 3.79 & 6.94 & 23.72 & 15.95 & 4.66 \\
\hline
\end{tabular}


(Table $\square$ ) contd......

\begin{tabular}{|c|c|c|c|c|c|c|c|c|}
\hline \multirow{2}{*}{ MF } & \multicolumn{4}{|c|}{ Elevation angle $\mathbf{6 0}^{\circ}$} & \multicolumn{4}{c|}{ Elevation angle 45 $^{\circ}$} \\
\cline { 2 - 9 } & $\min$ & $\max$ & mean & rms & $\min$ & max & mean & rms \\
\hline UNBabc & 5.60 & 19.25 & 12.95 & 3.78 & 6.90 & 23.62 & 15.87 & 4.64 \\
\hline
\end{tabular}

Table 5. Mean and rms of the wet tropospheric delay errors of the differences between the delays computed using the mapping functions and the ray trace results at $15^{\circ}$ and $30^{\circ}$ elevation angles.

\begin{tabular}{|c|c|c|c|c|c|c|c|c|}
\hline \multirow{2}{*}{ MF } & \multicolumn{9}{|c|}{ Elevation angle 30 } & \multicolumn{4}{c|}{ Elevation angle 15 $^{\circ}$} \\
\cline { 2 - 10 } & min & max & mean & rms & min & max & mean & Rms \\
\hline SA & 9.62 & 33.00 & 22.19 & 6.48 & 21.44 & 69.53 & 46.42 & 13.55 \\
\hline HO & 18.14 & 60.19 & 35.93 & 10.46 & 35.93 & 116.39 & 69.48 & 20.21 \\
\hline BL & 2.31 & -121.18 & -38.15 & 14.21 & 4.33 & -232.23 & -73.108 & 27.72 \\
\hline CH & 9.83 & 33.39 & 22.47 & 6.56 & 19.89 & 64.60 & 43.49 & 12.69 \\
\hline IF & 9.90 & 33.58 & 22.59 & 6.60 & 20.56 & 66.75 & 44.95 & 13.12 \\
\hline HE & 9.90 & 33.59 & 22.60 & 6.60 & 20.58 & 66.87 & 44.95 & 13.12 \\
\hline NI & 10.04 & 33.97 & 22.98 & 6.71 & 20.87 & 67.40 & 45.66 & 13.32 \\
\hline M0 & 9.83 & 33.37 & 22.45 & 6.56 & 19.92 & 64.69 & 43.56 & 12.71 \\
\hline B\&E & 10.06 & 34.02 & 22.91 & 6.69 & 22.02 & 70.69 & 47.74 & 13.92 \\
\hline UNBabc & 9.91 & 33.60 & 22.61 & 6.60 & 20.67 & 66.88 & 45.07 & 13.15 \\
\hline
\end{tabular}

Table 6. Mean and rms of the wet tropospheric delay errors of the differences between the delays computed using the mapping functions and the ray trace results at $9^{\circ}$ and $10^{\circ}$ elevation angles.

\begin{tabular}{|c|c|c|c|c|c|c|c|c|}
\hline \multirow{2}{*}{ MF } & \multicolumn{4}{|c|}{ Elevation angle 10 } & \multicolumn{4}{c|}{ Elevation angle 9 $^{\circ}$} \\
\cline { 2 - 9 } & min & max & mean & rms & min & max & mean & rms \\
\hline SA & 26.62 & 85.96 & 57.64 & 16.83 & 28.18 & 92.83 & 62.20 & 18.16 \\
\hline HO & 55.67 & 173.77 & 103.79 & 30.19 & 62.77 & 193.03 & 115.32 & 33.54 \\
\hline BL & 6.02 & -341.55 & -107.48 & 40.07 & 6.53 & -377.01 & -118.61 & 44.23 \\
\hline CH & 31.73 & 96.38 & 64.93 & 18.93 & 36.16 & 106.80 & 72.09 & 21.01 \\
\hline IF & 34.07 & 103.80 & 69.94 & 20.39 & 39.36 & 117.10 & 78.93 & 23.00 \\
\hline HE & 34.16 & 104.27 & 70.00 & 20.42 & 39.49 & 117.76 & 79.03 & 23.05 \\
\hline NI & 34.51 & 104.03 & 70.95 & 20.69 & 39.98 & 117.88 & 80.03 & 23.33 \\
\hline M0 & 31.95 & 85.7 & 65.38 & 19.06 & 35.65 & 107.99 & 72.80 & 21.22 \\
\hline B\&E & 38.99 & 117.11 & 79.38 & 23.12 & 46.06 & 135.25 & 91.80 & 26.73 \\
\hline UNBabc & 34.41 & 104.22 & 70.33 & 20.50 & 39.81 & 117.66 & 79.46 & 23.15 \\
\hline
\end{tabular}

Table 7. Mean and rms of the wet tropospheric delay errors of the differences between the delays computed using the mapping functions and the ray trace results at $5^{\circ}$ and $7^{\circ}$ elevation angles.

\begin{tabular}{|c|c|c|c|c|c|c|c|c|}
\hline \multirow{2}{*}{ MF } & \multicolumn{4}{|c|}{${\text { Elevation angle } 7^{\circ}}^{-}$} & \multicolumn{4}{c|}{${\text { Elevation angle } \mathbf{5}^{\circ}}^{\circ}$} \\
\cline { 2 - 9 } & $\min$ & $\max$ & mean & rms & min & max & mean & rms \\
\hline SA & 30.39 & 108.05 & 72.18 & 21.08 & 24.05 & 115.64 & 76.52 & 22.47 \\
\hline HO & 84.86 & 248.50 & 148.60 & 43.21 & 118.36 & 350.53 & 210.13 & 61.06 \\
\hline BL & 7.78 & -474.64 & -149.15 & 55.68 & 9.63 & -633.12 & -197.99 & 74.21 \\
\hline CH & 50.45 & 137.16 & 92.51 & 26.94 & 83.21 & 190.63 & 128.85 & 37.44 \\
\hline IF & 57.03 & 157.96 & 106.57 & 31.04 & 99.61 & 242.27 & 163.81 & 47.67 \\
\hline HE & 57.37 & 159.49 & 106.92 & 31.16 & 100.69 & 246.85 & 165.22 & 48.13 \\
\hline NI & 55.65 & 158.67 & 107.94 & 31.43 & 87.64 & 246.97 & 165.69 & 48.18 \\
\hline M0 & 46.26 & 140 & 94.49 & 27.50 & 66.64 & 200.90 & 136.01 & 39.51 \\
\hline B\&E & 70.89 & 195.52 & 133.20 & 38.76 & 134.74 & 359.11 & 231.47 & 67.35 \\
\hline UNBabc & 57.94 & 159.08 & 107.63 & 31.33 & 101.82 & 245.10 & 166.42 & 48.38 \\
\hline
\end{tabular}




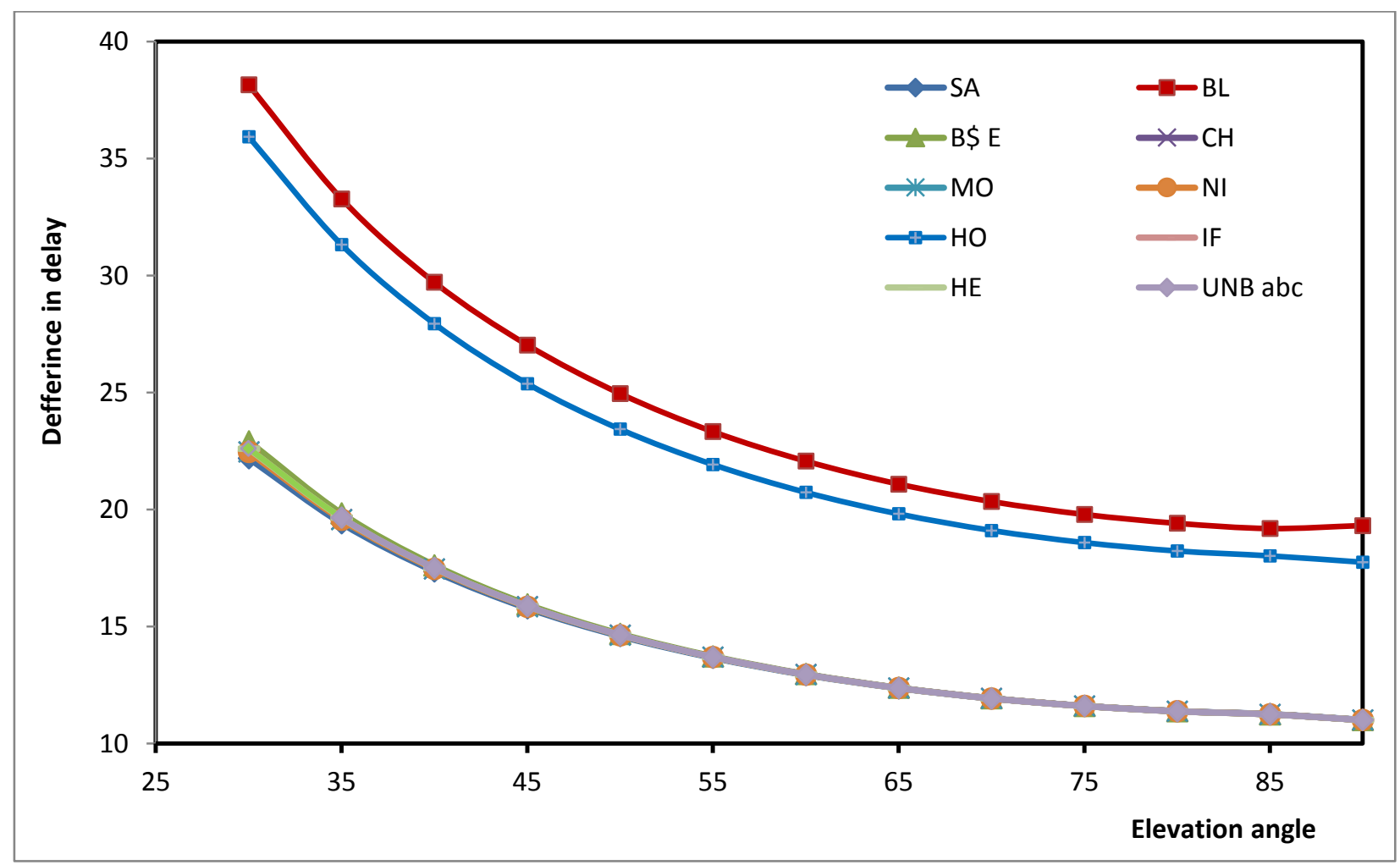

Fig. (5). Mean difference of the wet tropospheric delay errors between the delays computed using the mapping functions and the ray trace results for elevation angles from $30^{\circ}$ to $90^{\circ}$.

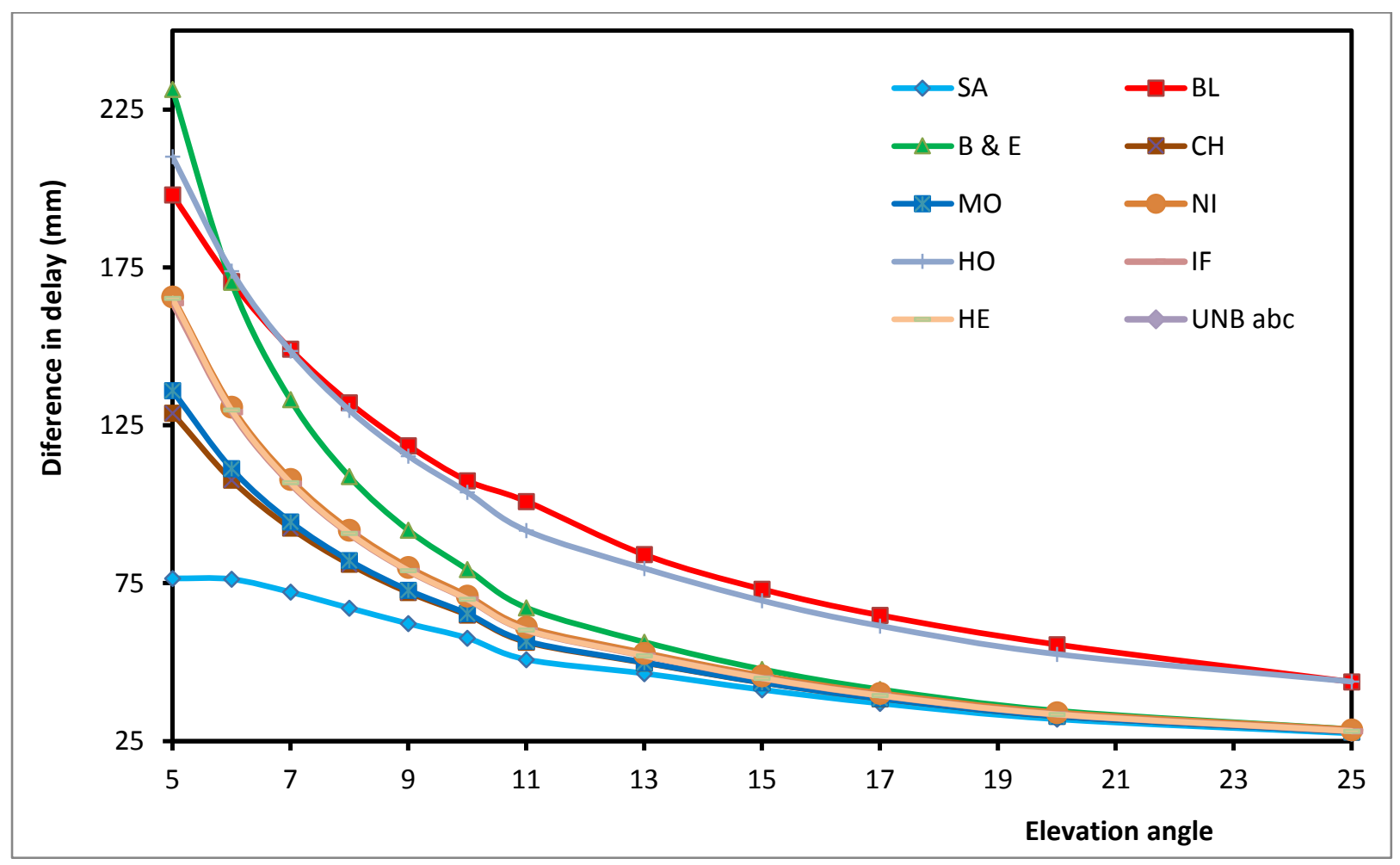

Fig. (6). Mean difference of the wet tropospheric delay errors between the delays computed using the mapping functions and the ray trace results for elevation angles from $5^{\circ}$ to $30^{\circ}$. 


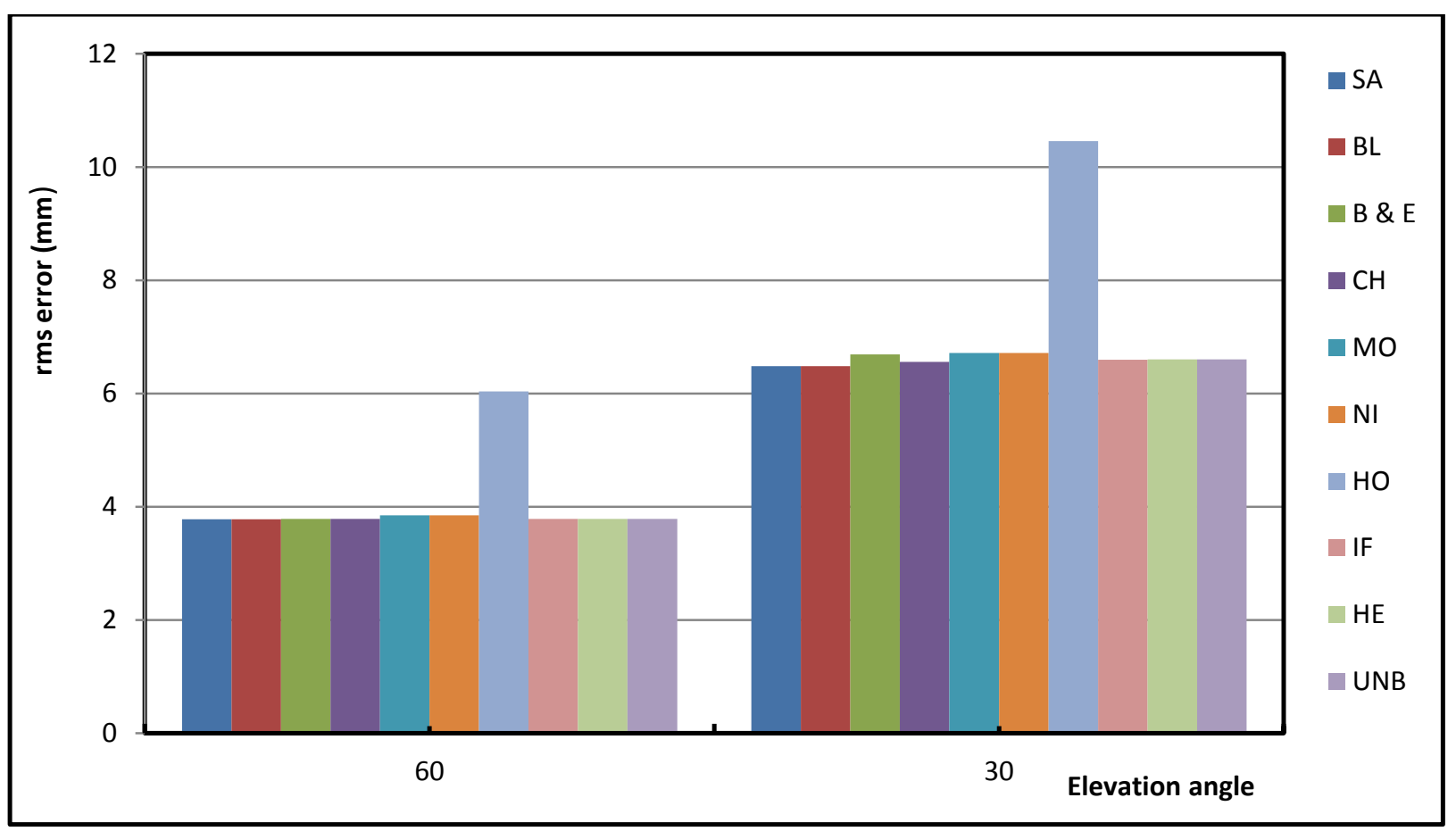

Fig. (7). Root mean square wet tropospheric delay errors about the mean of the differences between the delays computed using the mapping functions and the ray trace results for $30^{\circ}$ and $60^{\circ}$ elevation angles.

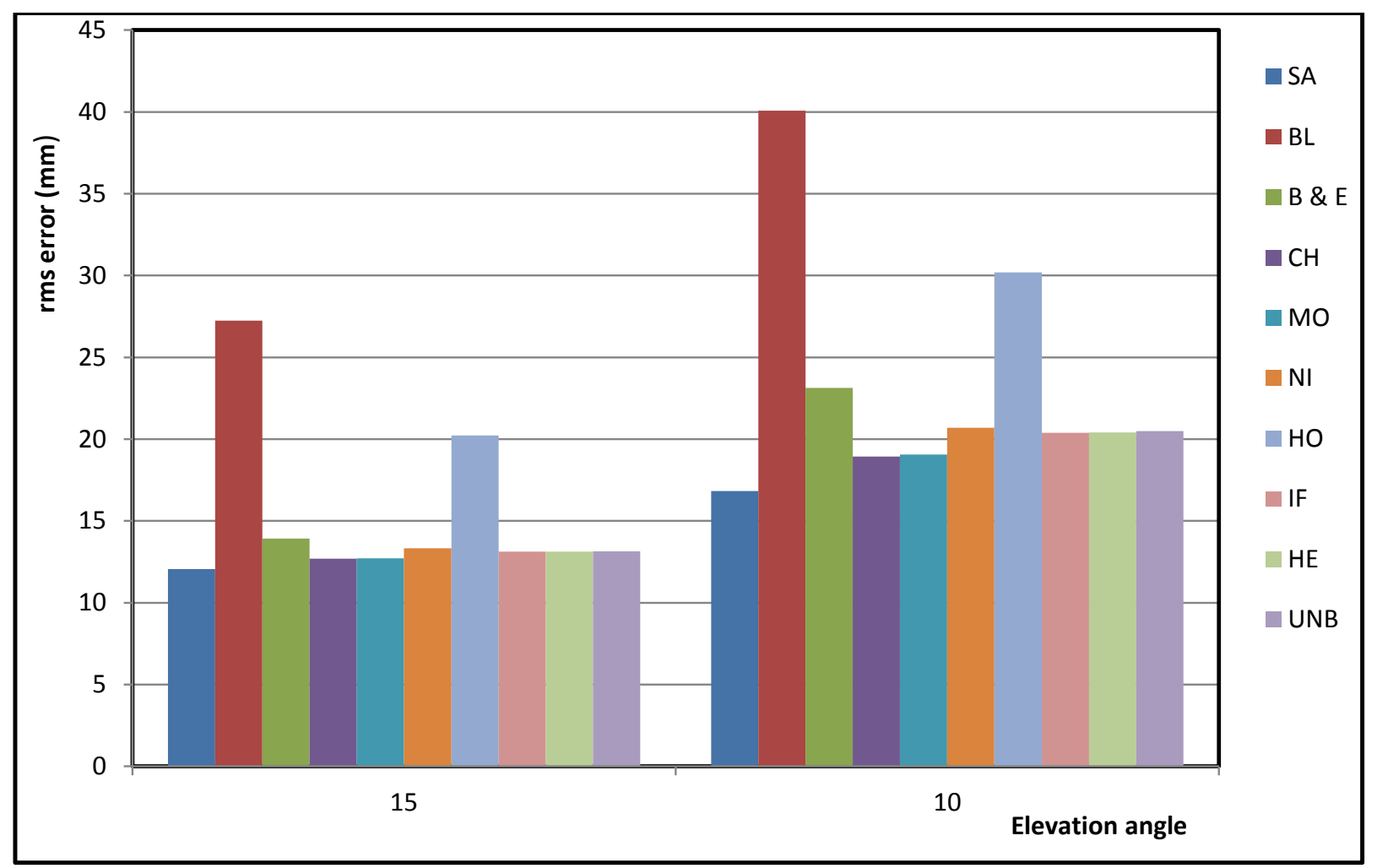

Fig. (8). Root mean square wet tropospheric delay errors about the mean of the differences between the delays computed using the mapping functions and the ray trace results for $10^{\circ}$ and $15^{\circ}$ elevation angles. 


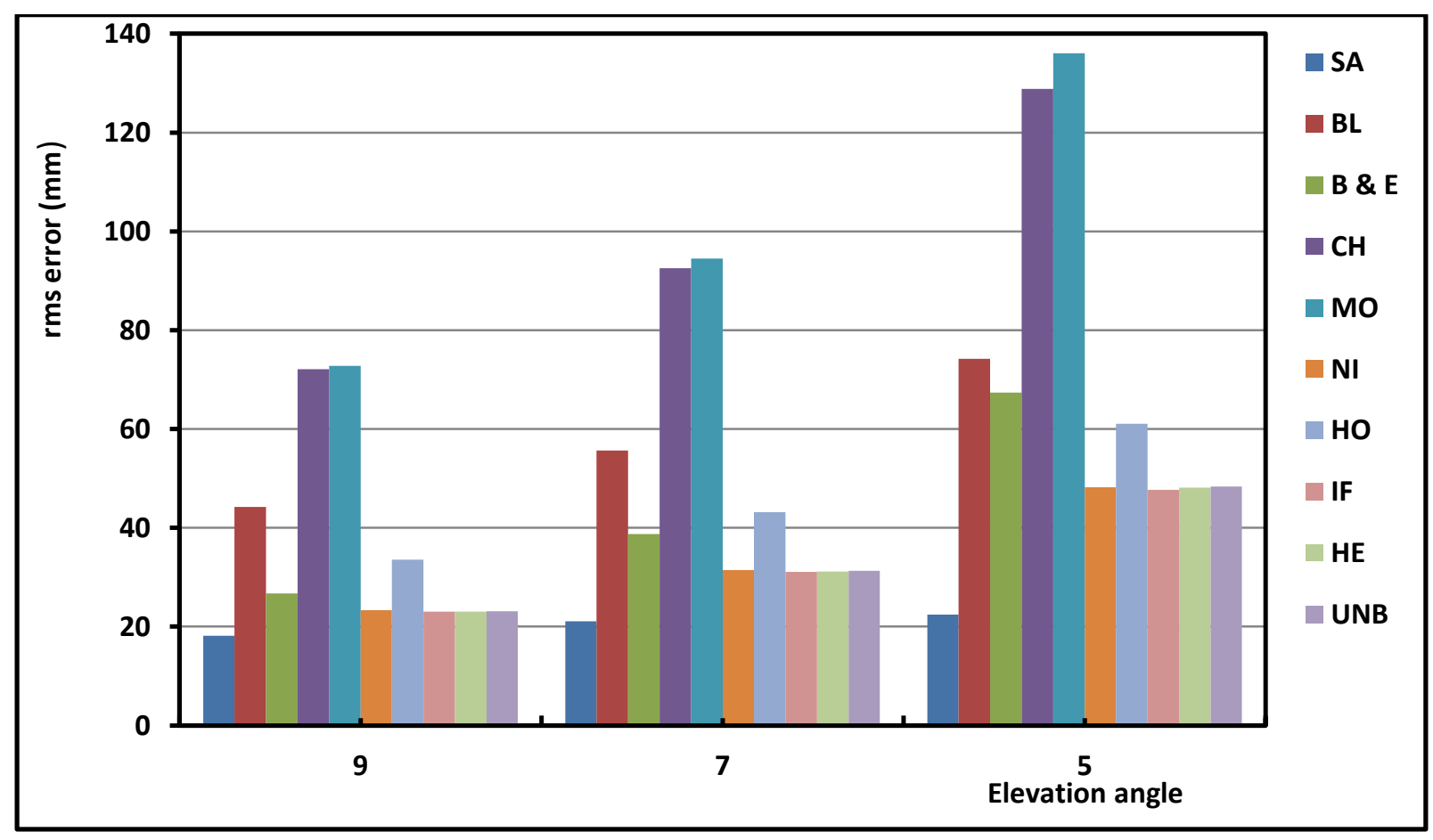

Fig. (9). Root mean square wet tropospheric delay errors about the mean of the differences between the delays computed using the mapping functions and the ray trace results for $5^{\circ}, 7^{\circ}$ and $9^{\circ}$ elevation angles.

For elevation angles above $30^{\circ}$, virtually all mapping functions except Hopfield MF and Black wet delay model yield errors of less than $23 \mathrm{~mm}$ with rms errors no more than $7 \mathrm{~mm}$. for elevation angle $30^{\circ}$, mean error difference between Hopfield MF and ray-trace model arrives $35.93 \mathrm{~mm}$ with rms $10.46 \mathrm{~mm}$ but for Black wet delay model the mean difference is $-38.15 \mathrm{~mm}$ and $\mathrm{rms}$ is $14.21 \mathrm{~mm}$, means that the Hopfield model and Black wet delay model is not citable for atmospheric conditions of Egypt. From analysis of the figures, SA, CH, IF, HE, NI, MO, B \& E and UNBabc mapping functions provide sub-centimeter accuracy for angles above $15^{\circ}$ with minimum difference between them no more than $4 \mathrm{~mm}$ in mean difference and $2 \mathrm{~mm}$ in rms values. For elevation angles below $10^{\circ}$, only a few of the functions are found to adequately meet the requirements currently imposed by space geodetic techniques.

The SA, $\mathrm{CH}$ and MO mapping functions are quite accurate at elevation angles above $10^{\circ}$. Since, at elevation angle $10^{\circ}$, the mean difference for SA mapping functions arrives $57.64 \mathrm{~mm}$ with $\mathrm{rms} 16.83 \mathrm{~mm}$, and $64.93 \mathrm{~mm}$ with rms $18.93 \mathrm{~mm}$ for $\mathrm{CH}$ mapping functions and $65.38 \mathrm{~mm}$ with $\mathrm{rms} 19.06 \mathrm{~mm}$ for MO mapping functions. For low elevation angles less than $10^{\circ}$, The Saastamoinen mapping functions perform well. However, the mean difference by SA mapping function compared to the ray tracing for the data set used at elevation angle $7^{\circ}$ is $76.52 \mathrm{~mm}$ with $\mathrm{rms} 22.97 \mathrm{~mm}$ and $76.52 \mathrm{~mm}$ with rms $22.97 \mathrm{~mm}$ for elevation angle $5^{\circ}$, comparing with $92.51 \mathrm{~mm}$ with rms $26.94 \mathrm{~mm}$ for $\mathrm{CH}$ mapping functions at $7^{\circ}$ elevation angle and $128.85 \mathrm{~mm}$ with rms $37.44 \mathrm{~mm}$ at elevation angle $5^{\circ}$.

Both the Hopfield and Black mapping functions differences with respect to ray tracing indicate some seasonal and/or latitudinal dependence. This might be caused by the use of nominal values for the tropopause height and temperature lapse rate. However, it seems likely that such nominal values will be used in space geodetic software since values of such parameters for specific sites and atmospheric conditions are generally not exactly known.

Table 8 summarizes the best five mapping functions based on the mean difference, rms and relative error as compared to the delay computed using ray trace model for Egypt. For this data set, the Saastamoinen, Chao, Moffett, Ifadis and Herring mapping functions provided the same level of accuracy for elevation angle more than $10^{\circ}$. For elevation angle less than $10^{\circ}$, as can be seen in Table $8 \mathrm{~b}$, and $8 \mathrm{c}$, the Saastamoinen, Chao and Moffett functions consecutively place first, second and third, respectively. The results states that if information is available on the vertical temperature and water vapor pressure distribution in the atmosphere, the Saastamoinen mapping function should be used. Otherwise, one of the mapping functions derived by Chao and Moffet should be used. 
Table 8. Rank of the five best mapping functions for Egypt, based on corresponding mean differences, rms and percent error with respect to those computed using the ray trace model.

\begin{tabular}{|c|c|c|c|c|c|c|c|c|c|}
\hline \multicolumn{5}{|c|}{ a) $30^{\circ}$ elevation angle } & \multicolumn{5}{|c|}{$15^{\circ}$ elevation angle } \\
\hline MF & Mean difference & rms & Percent error & rank & MF & Mean difference & rms & Percent error & rank \\
\hline SA & 22.19 & 6.48 & 8.24 & 1 & $\mathrm{CH}$ & 43.49 & 12.69 & 8.39 & 1 \\
\hline MO & 22.45 & 6.56 & 8.34 & 2 & MO & 43.56 & 12.71 & 8.40 & 2 \\
\hline $\mathrm{CH}$ & 22.47 & 6.56 & 8.35 & 3 & IF & 44.95 & 13.12 & 8.67 & 3 \\
\hline IF & 22.59 & 6.60 & 8.39 & 4 & $\mathrm{HE}$ & 44.95 & 13.12 & 8.67 & 4 \\
\hline $\mathrm{HE}$ & 22.60 & 6.60 & 8.40 & 5 & UNB & 45.07 & 13.15 & 8.70 & 5 \\
\hline \multicolumn{5}{|c|}{ b) $10^{\circ}$ elevation angle } & \multicolumn{5}{|c|}{$9^{\circ}$ elevation angle } \\
\hline MF & Mean difference & rms & Percent error & rank & MF & Mean difference & rms & Percent error & rank \\
\hline SA & 57.64 & 16.83 & 7.50 & 1 & SA & 62.20 & 18.16 & 7.31 & 1 \\
\hline $\mathrm{CH}$ & 64.93 & 18.93 & 8.45 & 2 & $\mathrm{CH}$ & 72.09 & 21.01 & 8.46 & 2 \\
\hline $\mathrm{MO}$ & 65.38 & 19.06 & 8.51 & 3 & $\mathrm{MO}$ & 72.80 & 21.22 & 8.55 & 3 \\
\hline IF & 69.94 & 20.39 & 9.10 & 4 & IF & 78.93 & 23.00 & 9.27 & 4 \\
\hline $\mathrm{HE}$ & 70.00 & 20.42 & 9.11 & 5 & $\mathrm{HE}$ & 79.03 & 23.05 & 9.28 & 5 \\
\hline \multicolumn{5}{|c|}{ c) $7^{\circ}$ elevation angle } & \multicolumn{5}{|c|}{$5^{\circ}$ elevation angle } \\
\hline MF & Mean difference & rms & Percent error & rank & MF & Mean difference & $\mathrm{rms}$ & Percent error & rank \\
\hline SA & 72.18 & 21.08 & 6.65 & 1 & SA & 76.52 & 22.47 & 5.13 & 1 \\
\hline $\mathrm{CH}$ & 92.51 & 26.94 & 8.52 & 2 & $\mathrm{CH}$ & 128.85 & 37.44 & 8.63 & 2 \\
\hline $\mathrm{MO}$ & 94.49 & 27.50 & 8.71 & 3 & $\mathrm{MO}$ & 136.01 & 39.51 & 9.11 & 3 \\
\hline IF & 106.57 & 31.04 & 9.82 & 4 & $\mathrm{HE}$ & 165.22 & 48.13 & 10.97 & 4 \\
\hline $\mathrm{HE}$ & 106.92 & 31.06 & 9.85 & 5 & IF & 163.81 & 47.67 & 11.07 & 5 \\
\hline
\end{tabular}

The SA, $\mathrm{CH}$, and Moffett mapping functions are quite accurate at very low elevation angles (less than $10^{\circ}$ ) than the other mapping functions as compared to the ray tracing for the data set used. Therefore, for high-precision applications, it is recommended that the mapping function derived by Saastamoinen model be used as the first choice. The second choice will be the Chao or the Moffett mapping function.

\section{CONCLUSION}

From the presented results, we have concluded that the wet component of the slant tropospheric delay can be predicted with sub-millimeter accuracy, using the Saastamoinen model, provided accurate measurements of surface meteorological data or site dependent parameters are available.

In spite of the large number of mapping functions we have analyzed, only a small group meet the high standards of modern space geodetic data analysis: Chao, Moffett, Ifidas and Herring mapping functions.

For elevation angle above 15, SA, CH, MO, IF, HE, NI, UNB and B\&E yield identical mean biases and the best total error performance. At lower elevation angles, SA, CH, MO, IF and HE are clearly superior. As regards the rms scatter about the mean, Saastamoinen mapping function performs the best for all elevation angle, followed closely by Chao and Moffett mapping functions respectively.

\section{CONFLICT OF INTEREST}

The authors confirm that this article content has no conflict of interest.

\section{ACKNOWLEDGEMENTS}

This work was not completed without the help of many other people. Firstly, my professors at public works department, they have provided me with more opportunities than I could have imagined. Thank you for believing in me, supporting me, and helping me along the way.

Also, the financial contribution of all members of the Egyptian Meteorological Authority for preparing, realizing and analyzing the measurements of temperature, pressure and humidity with different heights within their authority.

Finally, and most importantly, Sarah, for their love and support for all of my friends, students and laboratory for putting up with me while I prepared this paper. 


\section{REFERENCES}

[1] Rothacher M. Estimation of Station Heights with GPS. In: Drewes H, Dodson A, Fortes LP, Sánchez L, Sandoval P, Eds. Vertical Reference Systems. Berlin: Springer 2002; pp. 81-90

[http://dx.doi.org/10.1007/978-3-662-04683-8_17]

[2] Schaer S. Mapping and Predicting the Earth's Iionosphere using the Global Positioning System. PhD, Thesis. Bern, Switzerland: Astronomical Institute, University of Bern 1999.

[3] Hopfield H. Tropospheric Effect on Electromagnetically Measured Range: Prediction from Surface Weather Data. Radio Sci 1971; 6(3): 357-67.

[http://dx.doi.org/10.1029/RS006i003p00357]

[4] Leick A. GPS Satellite Surveying. New Jersey: John Wiley \& Sons 2004; p. 474.

[5] Ramjee P, Ruggieri M, Eds. Applied Satellite Navigation Using GPS, GALILEO and Augmentation Systems Artech House. Boston: Artech House Mobile Communications Series 2005.

[6] Forgues I. Study of the Tropospheric Projection Functions and Their Impacts in the GPS Positioning Memory of M Sc. Canada: University of Laval 1996.

[7] Mendes VB. Modeling the Neutral-Atmosphere Propagation Delay in Radiometric Space Techniques. PhD thesis. Canada: Department of Geodesy and Geomatics Engineering, University of New Brunswick 1998.

[8] Langely RB, Guo J. A New Tropospheric Propagation Delay Mapping Function for Elevation Angles to $2^{\circ}$. In: Proceeding of ION GPS/GNSS 2003, 16th International Technical Meeting of the satellite Division of the Institute of Navigation, Portland. 2003 ; pp. $386-96$.

[9] Herring TA. Modeling Atmospheric Delays in the Analysis of Space Geodetic Data. In: De Munck JC, Spoelstra TATh, Eds. Proceedings of the Symposium on Refraction of Trans-Atmospheric Signals in Geodesy. Netherlands: Geodetic Commission, Publications on Geodesy, No. 36 1992; pp. 157-64.

[10] Davis JL, Herring TA, Shapiro II, Rogers AE, Elgered G. Geodesy by Radio Interferometry: Effects of Atmospheric Modeling Errors on Estimates of Baseline Length. Radio Sci 1985; 20(6): 1593-607. [http://dx.doi.org/10.1029/RS020i006p01593]

[11] Lanyi G. Tropospheric Delay Effects in Radio Interferometry Telecommunications and Data Acquisition Progress, JPL Technical Report 42-78, Jet Propulsion Laboratory, Pasadena, Calif, USA. 1984; pp. 152-9.

[12] Ifadis IM. The Atmospheric Delay of Radio Waves: Modeling the Elevation Dependence on a Global Scale School of Electrical and Computer Engineering, Chalmers University of Technology, Goteborg, Sweden, Technical Report No 38L. 1986; p. 115.

[13] Niell AE. Global Mapping Functions for the Atmosphere Delay at Radio Wavelengths. J Geophys Res 1996; 101(B2): $3227-46$. [http://dx.doi.org/10.1029/95JB03048]

[14] Black HD, Eisner A. Correcting Satellite Doppler Data for Tropospheric Effects. J Geophys Res 1984; 89(D2): $2616-26$. [http://dx.doi.org/10.1029/JD089iD02p02616]

[15] Neill AE. Improved Atmospheric Mapping Functions for VLBI and GPS. Earth Planets Space 2000; (52): 699-702. [http://dx.doi.org/10.1186/BF03352267]

[16] Saastamoinen J. Atmospheric Correction for Troposphere and Stratosphere in Radio Ranging if Satellites Geophysical Monograph, 15, American Geophysical Union, Washington, DC, USA. 1972; pp. 247-52. [http://dx.doi.org/10.1029/GM015p0247]

[17] Black HD. An Easily Implemented Algorithm for the Tropospheric Range Correction. J Geophys Res 1978; 38(B4): 1825-8. [http://dx.doi.org/10.1029/JB083iB04p01825]

[18] Marini JW. Correction of Satellite Tracking Data for an Arbitrary Tropospheric Profile. Radio Sci 1972; 7(2): $223-31$. [http://dx.doi.org/10.1029/RS007i002p00223]

[19] Chao CC. A model for Tropospheric Calibration from Daily Surface and Radiosonde Balloon Measurements. JPL Technical Memorandum Jet Propulsion Laboratory, Pasadena, CA 1972; 350-91.

[20] Moffett JB. Program Requirements for Two-Minute Integrated Doppler Satellite Navigation Solution. Technical Memorandum TG Applied Physics Laboratory, The Johns Hopkins University, and Laurel, MD, 1973; 819-1.

[21] Younes SA. 2016 Modeling Investigation of Wet Tropospheric Delay Error and Precipitable Water Vapor Content in Egypt. Egypt: J. Remote Sensing Space Sci 2016; 19: pp. (2)333-42.

[22] Thayer G. A Rapid and Accurate Ray Tracing Algorithm for a Horizontally Stratified Atmosphere. Radio Sci 1967; 1(2): $249-52$. [http://dx.doi.org/10.1002/rds196722249]

(C) 2017 Sobhy Abdel-Monam Younes.

This is an open access article distributed under the terms of the Creative Commons Attribution 4.0 International Public License (CC-BY 4.0), a copy of which is available at: (https://creativecommons.org/licenses/by/4.0/legalcode). This license permits unrestricted use, distribution, and reproduction in any medium, provided the original author and source are credited. 